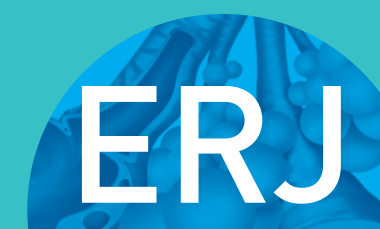

open research

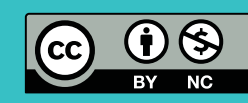

\section{GOLD criteria overestimate airflow limitation in one-third of cases in the general Finnish population}

\author{
Annette Kainu (10) ${ }^{1}$, Kirsi Timonen ${ }^{2,3}$, Ari Lindqvist ${ }^{4}$ and Päivi Piirilä ${ }^{5}$
}

Affiliations: ${ }^{1}$ Heart and Lung Center, Peijas Hospital, University of Helsinki and Helsinki University Hospital, Helsinki, Finland. ${ }^{2}$ Dept of Clinical Physiology, Central Hospital of Central Finland, Jyväskylä, Finland. ${ }^{3}$ Dept of Clinical Physiology and Nuclear Medicine, Kuopio University Hospital and University of Eastern Finland, Kuopio, Finland. ${ }^{4}$ Research Unit of Pulmonary Diseases, University of Helsinki and Helsinki University Hospital, Helsinki, Finland. ${ }^{5}$ Dept of Clinical Physiology and Nuclear Medicine, HUS Medical Imaging Center, University of Helsinki and Helsinki University Hospital, Helsinki, Finland.

Correspondence: Annette Kainu, HUCH Heart and Lung Center, Peijas Hospital, University of Helsinki and Helsinki University Hospital, PO Box 900, 00029 HUS, Finland. E-mail: annette.kainuahelsinki.fi

ABSTRACT The Global Initiative for Chronic Obstructive Lung Disease (GOLD) diagnostic criteria for chronic obstructive pulmonary disease (COPD) use a fixed threshold of forced expiratory volume in $1 \mathrm{~s}$ $(\mathrm{FEV} 1)$ /forced vital capacity $(\mathrm{FVC})$ ratio $(<0.70)$ in post-bronchodilation spirometry to indicate disease, which has been shown to underestimate and overestimate disease prevalence in younger and older adults, respectively, whilst criteria based on reference values have better accuracy. Differences in reference values have limited their use in international studies. However, the new Global Lung Function Initiative reference values (GLI2012) showed FEV1/FVC to be the least dependent on ethnicity. The aim of this study was to assess the prevalence of airflow limitation with GLI2012 and the degree of underdetection or overestimation related to the use of GOLD in the general population.

A Finnish population sample of 1323 subjects (45\% male) with post-bronchodilation spirometry was studied.

80 subjects $(6.0 \%)$ and 55 subjects $(4.2 \%)$ were identified with airflow limitation with GOLD and GLI2012 criteria, respectively. The proportion of overestimation with GOLD increased with age from $25 \%$ of cases in 50-year-olds to $54 \%$ in 70 -year-olds. Using $\mathrm{z}$-score-based grading resulted in more dispersion in severity grading.

In conclusion, the GOLD criteria cause a marked overestimation already from 50-year-olds and should be replaced with the GLI2012 criteria to improve diagnostic accuracy.

@ERSpublications

GOLD criteria overestimate COPD, with $>30 \%$ of cases having normal spirometry using GLI2012 reference values http://ow.ly/IyGr302sZTs

Received: Nov 082015 | Accepted after revision: July 152016

Support statement: The FinEsS-Helsinki study has received funding from the Special Governmental Subsidy for Health Sciences Research (project codes TYH1235, TYH 2303, TYH 4251 and TYH 2013354). A. Kainu has received a research grant from the Finnish Anti-tuberculosis Foundation and Jalmari and Rauha Ahokas Foundation. Funding information for this article has been deposited with the Open Funder Registry.

Conflict of interest: Disclosures can be found alongside this article at openres.ersjournals.com

Copyright $\odot$ ERS 2016. This article is open access and distributed under the terms of the Creative Commons Attribution Non-Commercial Licence 4.0. 


\section{Introduction}

In the early 1990s, chronic obstructive bronchitis was poorly understood, mostly under-recognised and with limited research focus. In the late 1990s, the international recognition of the need to improve diagnostics and research in the disease spectrum then coined with the name chronic obstructive pulmonary disease (COPD) led to the formation of the Global Initiative for Chronic Obstructive Lung Disease (GOLD) framework with a major effort aiming for earlier recognition and improved research understanding of this condition [1]. Until then, the main focus of national and international efforts in obstructive airways diseases had been in asthma.

The GOLD framework set forth to improve earlier diagnostics by making diagnostic criteria easily accessible and understandable. Whilst it was already understood that criteria for airflow limitation are dependent on sex, height and age (and also to some extent ethnicity), the GOLD guidelines introduced a simplified "rule of thumb" of the so-called fixed-limit criterion of forced expiratory volume in $1 \mathrm{~s}(\mathrm{FEV} 1) /$ forced vital capacity $(\mathrm{FVC})<0.70$ in post-bronchodilation spirometry indicating airflow limitation in order to make the diagnosis easier [1]. Reference values vary from one population to another and criteria based on reference values were seen to introduce bias into research efforts. As population reference values vary greatly both in models and lower limits of normal (LLNs), their use was considered difficult to advocate and distribute internationally [1].

There is a large body of knowledge that criteria based on reference values are superior to fixed-limit criteria in the diagnosis of airflow limitation consistent with COPD [2-9]. Selected population studies highlighting the differences found between criteria based on fixed limits and reference values are summarised in table 1. In addition to the differences between the reference values used and their representativeness in the study population, the extent of difference of prevalence estimates is affected by age and sex distribution and the prevalence of smoking in the study population. COPD is a multicomponent disease and the use of a simplified criterion of a fixed limit of FEV1/FVC poses a risk of excessive simplification of a clinical entity that is necessarily complex [31]. In a recent review of the clinical relevance between these two criteria, the conclusion was that when these two criteria were in disagreement, an alternative diagnosis should be considered, particularly among older individuals with less severe airflow limitation where the criteria based on reference values performed better [32]. Even the GOLD guidelines included a recommendation in the 2011 revision that criteria relative to reference values should be considered in the elderly, as the fixed-limit criterion causes overdiagnosis in ageing populations [33]. However, it did not specify what age should be considered "old". In the 2015 update, the GOLD guidelines already recommend the use of reference values whenever available; however, the main document still endorses the fixed-limit criterion as the main diagnostic criterion [34].

Until recently the problem of a lack of uniform reference values has invalidated comparisons between populations and different geographical areas. In 2012, the European Respiratory Society Global Lung Function Initiative introduced the first global reference values for spirometry with the GLI2012 reference equations [10]. These all-age reference values provide models for different ethnic backgrounds using the generalised additive model for location, scale and shape (GAMLSS) model [23, 35]. The method summarises the changing distribution by three curves representing the median $(M)$, coefficient of variation (S) and skewness, the latter expressed as after a Box-Cox power $\lambda(\mathrm{L})$ transformation $[23,35]$. The FEV1/ FVC ratio was found to be the least dependent on ethnicity of all evaluated spirometry variables [10]. Although the validity of the global reference equations has been evaluated in only very few population-based samples, these reference values provide for the first time a uniform model that depicts decline of lung function with age, sex and height, and enable the use of LLN criteria for epidemiology and research between different populations $[10,36]$. The GLI2012 reference values have been endorsed by all major international respiratory societies [10]. In a recent study among very old adults ( $\geqslant 80$ years old) from Belgium, only airflow limitation defined by GLI2012 was independently associated with mortality, whereas subjects fulfilling the GOLD criterion without reduced FEV1/FVC < LLN had no significantly higher risk of mortality or hospitalisation [30].

The aim of our study was to assess the prevalence of airflow limitation with GLI2012, and the degree of underdetection and overestimation of airflow limitation suggestive of COPD related to the use of the GOLD criterion of a fixed limit of $\mathrm{FEV} 1 / \mathrm{FVC}<0.70$ in post-bronchodilation spirometry in the general population. In addition, we aimed to evaluate the GOLD grading of airflow limitation compared with the z-score-based grading of distribution of severity of impairment.

\section{Materials and methods}

We used data from the two Finnish centres participating in the FinEsS studies in respiratory epidemiology. The study population was randomly sampled from the National Population Registry in 10-year age cohorts and represents adults aged 20-75 years old. The study protocol has been described in detail previously 
TABLE 1 General population studies comparing the diagnostic criteria of forced expiratory volume in $1 \mathrm{~s}(\mathrm{FEV} 1) /$ forced vital capacity (FVC) $<0.70$ and FEV1/FVC $<$ lower limit of normal (LLN)

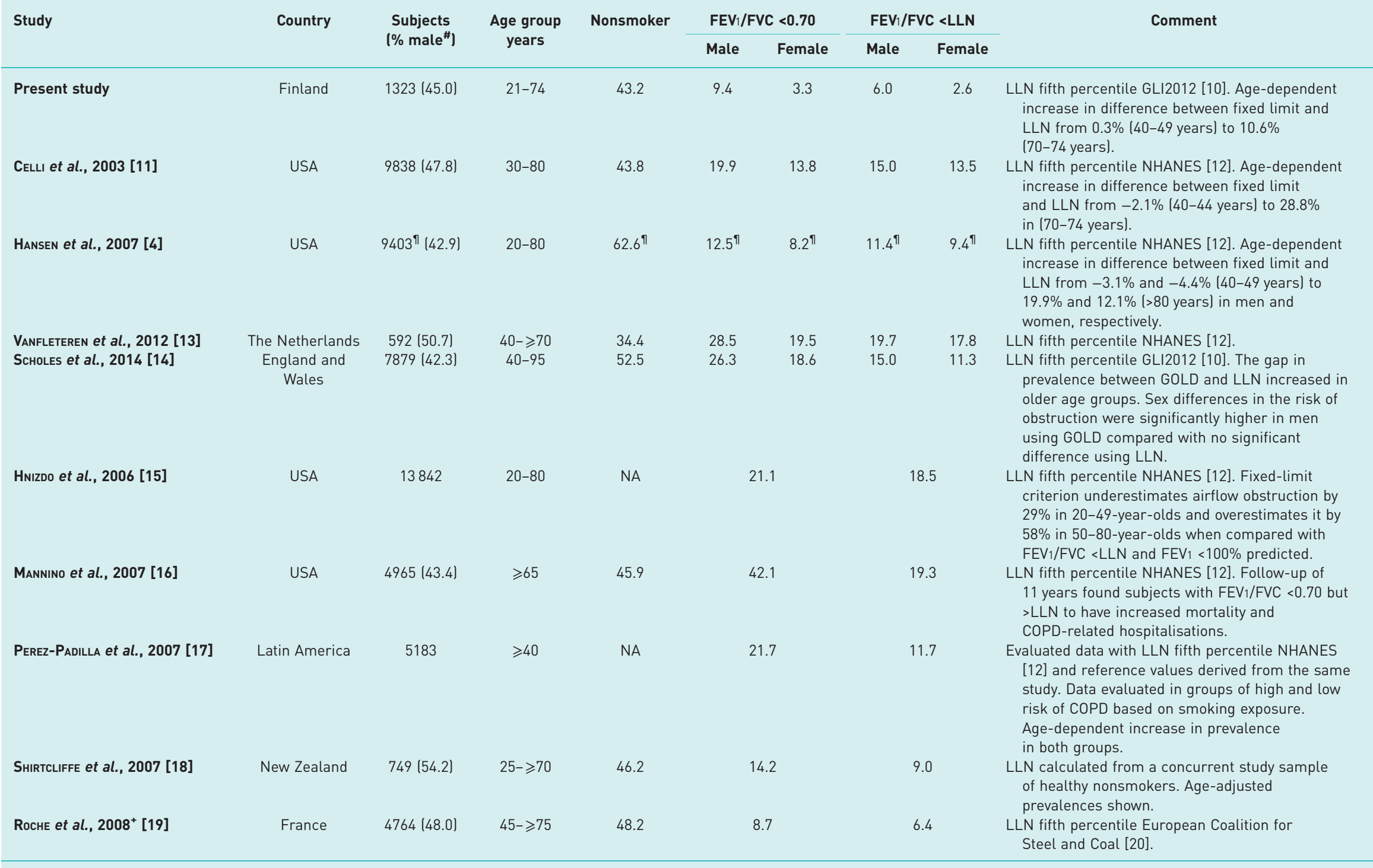


TABLE 1 Continued

\begin{tabular}{|c|c|c|c|c|c|c|c|}
\hline \multirow[t]{2}{*}{ Study } & \multirow[t]{2}{*}{ Country } & \multirow{2}{*}{$\begin{array}{c}\text { Subjects } \\
(\% \text { male } \mid \text { I }\end{array}$} & \multirow{2}{*}{$\begin{array}{l}\text { Age group } \\
\text { years }\end{array}$} & \multirow[t]{2}{*}{ Nonsmoker } & $\mathrm{FEV}_{1} / \mathrm{FVC}<0.70$ & $\mathrm{FEV}_{1} / \mathrm{FVC}<\mathrm{LLN}$ & \multirow[t]{2}{*}{ Comment } \\
\hline & & & & & Female & Female & \\
\hline SWANNEY et al., 2008 [7] & $\begin{array}{c}\text { The Netherlands } \\
\text { UK } \\
\text { USA }\end{array}$ & $\begin{array}{l}4557 \text { Dutch } \\
24604 \text { UK } \\
6829 \text { USA }\end{array}$ & $17-\geqslant 90$ & NA & $\begin{array}{l}20.5 \\
13.4 \\
21.8\end{array}$ & $\begin{array}{l}12.3 \\
14.1 \\
15.5\end{array}$ & $\begin{array}{l}\text { LLN from Dutch reference values from that } \\
\text { substudy, for UK data LLN of FALASCHETI et al. [21] } \\
\text { and for USA the fifth percentile LLN of NHANES } \\
\text { [12]. GOLD guidelines caused false-positive } \\
\text { rates of up to } 60 \% \text { when applied to } \\
\text { entire populations. }\end{array}$ \\
\hline$V_{A z}$ Fragoso et al., 2010 [22] & USA & 3502 (47.8) & $40-80$ & 40.8 & 27.0 & 13.8 & $\begin{array}{l}\text { LLN based on LMS method LLN fifth percentile } \\
\text { from study sample [23]. }\end{array}$ \\
\hline GARCIA-RIO et al., 2011 [24] & Spain & $3802^{\S}$ & $40-80$ & $27.6^{5}$ & 10.2 & 5.5 & $\begin{array}{l}\text { LLN based on Roca et al. [25]. A subsample of } 885 \\
\text { subjects }(58.2 \% \text { malel was further evaluated with } \\
\text { subjects diagnosed with GOLD but normal with } \\
\text { LLN presenting worse self-reported quality of life, } \\
\text { but similar exercise, frequency of exacerbations } \\
\text { and indices of systemic effects. }\end{array}$ \\
\hline LAMPRECHt et al., 2011 [26] & Austria & $1258(54.5)$ & $\geqslant 40$ & 43.1 & 24.2 & 15.3 & $\begin{array}{l}\text { LLN fifth percentile NHANES [12]. Discordance } \\
\text { increased with age. Discordant cases more often } \\
\text { older, male and never-smokers, and had fewer } \\
\text { respiratory symptoms and better FEV1. Discordant } \\
\text { cases had heart disease significantly more often. }\end{array}$ \\
\hline WAKED et al., 2011 [27] & Lebanon & $2201(48.4)$ & $\geqslant 40$ & 33.3 & 9.7 & 12.5 & $\begin{array}{l}\text { LLN based on LMS method fifth percentile from } \\
\text { study sample [23]. The number of never-smokers } \\
\text { was small and the LLN-based definition showed a } \\
\text { parabolic prevalence estimation by age. }\end{array}$ \\
\hline DANIELSSON et al., 2012 [28] & Sweden & $548(48.2)$ & $\geqslant 40$ & 42.7 & 15.7 & 9.3 & LLN fifth percentile NHANES [12]. \\
\hline VAN DIJK et al., 2015 [29] & Canada & $4882(43.0)$ & $40-\geqslant 80$ & 43.0 & 17.0 & 11.2 & $\begin{array}{l}\text { LLN fifth percentile NHANES [12]. Evaluated the } \\
\text { clinical significance of fixed-ratio- versus } \\
\text { LLN-based criteria. Fixed ratio alone may lead to } \\
\text { misdiagnosis. FEV } / \text { FVC <LLN and a low FEV is } \\
\text { strongly associated with clinical outcomes. } \\
\text { Guidelines should be reconsidered to require } \\
\text { both spirometric abnormalities to reduce } \\
\text { overdiagnosis of COPD. }\end{array}$ \\
\hline TURKESHI et al., 2015 [30] & Belgium & $411(37.0)$ & $\geqslant 80$ & 69.6 & 27.0 & 9.2 & $\begin{array}{l}\text { LLN fifth percentile GLI2012 [10]. Only airflow } \\
\text { limitation by GLI2012 was independently } \\
\text { associated with mortality. Subjects with FEV } / \text { FVC } \\
<0.70 \text { but above GLI2012 LLN had no significantly } \\
\text { higher risk of mortality or hospitalisation. }\end{array}$ \\
\hline
\end{tabular}

Data are presented as $\mathrm{n}$ or \%, unless otherwise stated. GLI2012: Global Lung Function Initiative reference values; NHANES: National Health and Nutrition Examination Survey; GOLD:

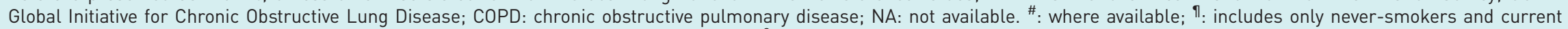
smokers from the population sample; ${ }^{+}$: primary care sample of routine preventive visits; ${ }^{\S}$ : full sample, study analysis of health-related quality of life pertaining to a smaller subsample of subjects with no COPD. 
[37-39]. The study has been approved by the Helsinki University Central Hospital Board of Ethics (Helsinki, Finland) and Länsi-Pohja Hospital Board of Ethics (Kemi, Finland).

628 adults (41.4\% male) and 695 adults (48.3\% male) participated in the clinical study in Helsinki and Kemi, respectively, between 1998 and 2003, including post-bronchodilation spirometry fulfilling predefined quality criteria. All participants were of Caucasian ethnic origin. Smoking history was evaluated by an interview questionnaire administered by a nurse and subjects were categorised as nonsmokers, ex-smokers or current smokers. All subjects having smoked any amount of cigarettes, cigars or pipe tobacco during the previous year were classified as current smokers. Ever-smokers were all current smokers and former smokers. Former smokers were required to have quit smoking at least 1 year previously, but to have smoked at least one cigarette per day for 1 year previously. In Kemi, a nonresponder study was conducted in which younger smoking males were found to be less likely to participate in the survey. However, this did not affect the study results significantly [39].

Airflow limitation in the lower airways was defined in this study by spirometry. Spirometry was completed following American Thoracic Society criteria [40] with bronchodilation testing using $400 \mu \mathrm{g}$ salbutamol aerosol in two $200 \mu \mathrm{g}$ doses using a spacer (Ventoline Evohaler with Volumatic; GlaxoSmithKline, Brentford, UK). Only post-bronchodilation values of FVC, FEV1 and the FEV1/FVC ratio after bronchodilation were analysed and reported. The descriptive statistics of the study sample are outlined in table 2. The prevalence of smoking in different age categories in this study was at a similar level to other population studies of the time (e.g. the Health 2000 study [41]), thus the sample would seem to be representative of the general population also in terms of exposure levels.

GLI2012 reference values for Caucasians indicated airflow limitation if the FEV1/FVC ratio in the post-bronchodilation spirometry was below the defined fifth percentile LLN of z-score -1.645 [10]. GOLD criteria define airflow limitation as post-bronchodilation $\mathrm{FEV} 1 / \mathrm{FVC}<0.70$ [34]. A true-positive case of airflow limitation consistent with COPD was defined as a case with FEV1/FVC < LLN and FEV $1 / \mathrm{FVC}$ $<0.70$, a false-negative case was defined as a case with FEV1/FVC $<$ LLN but FEV1/FVC $\geqslant 0.70$ and a false-positive case was defined as a case with FEV1/FVC $\geqslant$ LLN but FEV1/FVC $<0.70$. The false-positive rate is the number of false-positive cases per study sample expressed as a percentage. The proportion of false-positive cases of all cases identified using the GOLD criterion is false positives divided by the sum of true positives and false positives.

The grading of degree of severity of airflow limitation was evaluated with the decreased ventilatory capacity, i.e. lowered $\mathrm{FEV}_{1}$ relative to $\mathrm{FEV}_{1} \%$ pred with the GLI2012 reference value as suggested by the GOLD guidelines and relative to the individually calculated z-score as suggested by QUANJER et al. [10, 42]. In the GOLD recommendation, values of FEV1 \% pred $\geqslant 80$ were considered mild COPD, 50-79 as moderate COPD, 30-49 as moderately severe COPD and $<30$ as severe COPD [34]. In the z-score-based

\section{TABLE 2 Characteristics of the study population}

\begin{tabular}{lcc} 
& Male & Female \\
\hline Subjects & 596 & 727 \\
Age years & $48.8 \pm 13.2$ & $48.2 \pm 13.0$ \\
Height cm & $176.5 \pm 6.6$ & $163.0 \pm 6.1$ \\
BMI kg-m ${ }^{-2}$ & $26.4 \pm 3.9$ & $25.9 \pm 4.9$ \\
FEV1 L & $3.9 \pm 0.9$ & $2.9 \pm 0.6$ \\
FVC L & $4.9 \pm 0.9$ & $3.5 \pm 0.6$ \\
FEV1/FVC & $0.796 \pm 0.082$ & $0.822 \pm 0.063$ \\
FEV1 Z-score GLI2012 [10] & $0.04 \pm 1.07$ & $0.11 \pm 0.94$ \\
FVC z-score GLI2012 [10] & $-0.02 \pm 0.90$ & $-0.03 \pm 0.84$ \\
FEV1/FVC z-score GLI2012 [10] & $0.09 \pm 1.07$ & $0.19 \pm 0.86$ \\
Smoking status & & 52.8 \\
$\quad$ Nonsmoker & 31.4 & 22.3 \\
Ex-smoker & 36.4 & 24.9 \\
Current smoker & 32.2 & 7.0 \\
Physician-diagnosed asthma & 6.4 & 2.8 \\
Physician-diagnosed COPD & 2.9 &
\end{tabular}

Data are presented as $\mathrm{n}$, mean $\pm \mathrm{SD}$ or $\%$. BMI: body mass index; FEV1: forced expiratory volume in $1 \mathrm{~s}$; FVC: forced vital capacity; GLI2012: Global Lung Function Initiative reference values; COPD: chronic obstructive pulmonary disease. 
assessment of FEV1, individual $\mathrm{z}$-score values $>-2$ were considered mild, between -2 and -2.5 as moderate, between -2.5 and -3 as moderately severe, between -3 and -4 as severe, and $<-4$ as very severe impairment of the ventilatory capacity [42].

The GLI2012 predicted values and z-scores for each study participant were calculated using R (version 2.15.1; www.cran-R.org) with the macro provided by the Global Lung Function Initiative [43]; all other analyses were conducted using SPSS Statistics for Macintosh version 22.0 (IBM, Armonk, NY, USA). The Chi-squared test was used to compare groups and the Mantel-Haenszel Chi-squared test was used for trends. A p-value of 0.05 was considered significant in all analyses.

\section{Results}

The distribution of post-bronchodilation FEV1/FVC relative to GLI2012 reference values versus the absolute $\mathrm{FEV} 1 / \mathrm{FVC}$ ratio is shown in figure 1. The GOLD criteria identified overall $6.0 \%$ of subjects with airflow limitation; $9.4 \%$ of males and $3.3 \%$ of females $(\mathrm{p}<0.001)$. Correspondingly, the GLI2012 criteria identified $4.2 \%$ of subjects with airflow limitation; $6.0 \%$ and $2.6 \%$ of males and females, respectively $(\mathrm{p}=0.002)$. Among subjects with airflow limitation identified by GOLD, 39.3\% of cases were false positive in males and $25.0 \%$ of cases were false positive in females $(p=0.12)$. The rate of false positives increases with age in both males and females, as shown in figure 2 . The rate of false positives increases slightly but not significantly with height: $1.4 \%$ for subjects $<160 \mathrm{~cm}, 2.2 \%$ for subjects $160-179 \mathrm{~cm}$ and $2.5 \%$ for subjects $\geqslant 180 \mathrm{~cm}(\mathrm{p}=0.713)$. Of the false-positive subjects $(\mathrm{n}=28)$, taller subjects had higher mean $\mathrm{z}$-scores for $\mathrm{FEV} 1 / \mathrm{FVC}$ for subjects $<160(-1.57,95 \%$ CI $-1.79--1.35), 160-179(-1.26,95 \%$ CI $-1.39--1.14)$ and $>180 \mathrm{~cm}(-1.13,95 \% \mathrm{CI}-1.36--0.90)$, as shown in figure 3 . The proportion of false positives of all detected cases was $45.8 \%$ in subjects $\geqslant 60$ years of age (table 3 ), but false positives were found already in subjects aged 40-49 years. However, the numbers of cases in the younger age categories were limited.

As the GOLD criteria are prone to overdiagnosis of older subjects with normal FEV1/FVC based on LLN of reference values, the excess cases are found mostly in the mild category with normal FEV1, as shown in table 4. These subjects have both normal FEV1/FVC and FEV1 based on LLN of reference values. In the moderate to severe categories, the population prevalences are thus equal. Use of simplified percentage of predicted criteria (GOLD grading) failed to identify the individual variation in the LLN in the older age groups and thus more subjects end up in the moderate COPD category. Figure 4 illustrates the relationship between FEV1 \% pred GLI2012 and the individually calculated FEV1 z-score in the whole population sample. Using $80 \%$ of predicted overidentifies reduced ventilatory capacity at the population level in 45 subjects (3.4\%).

\section{Discussion}

The GOLD criteria were originally introduced to improve diagnostics to facilitate earlier identification of subjects with COPD [1]. However, the criteria are known to overdiagnose older individuals [2, 3, 7, 18, 22].

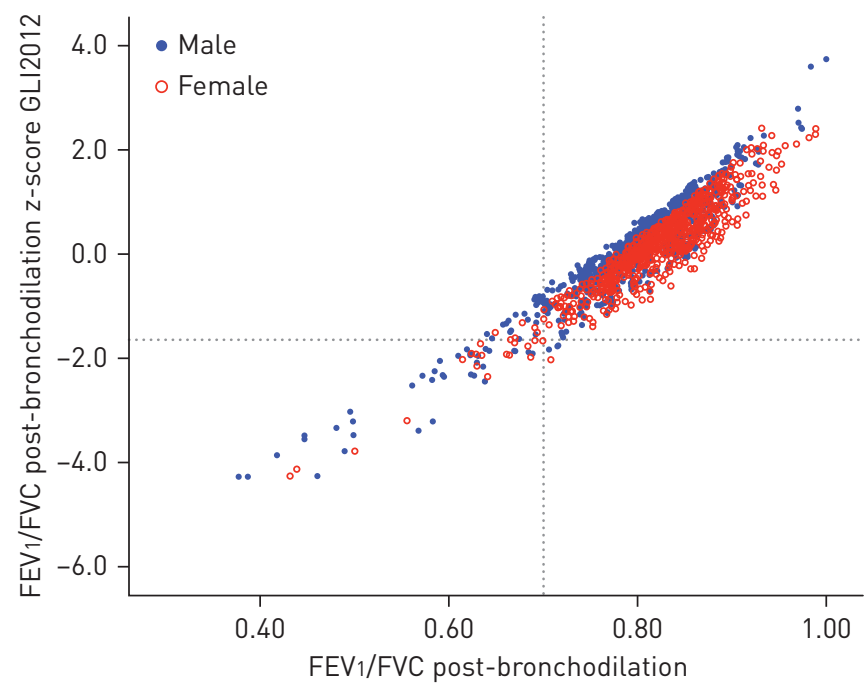

FIGURE 1 Distribution of post-bronchodilation forced expiratory volume in $1 \mathrm{~s}\left(\mathrm{FEV}_{1}\right) /$ forced vital capacity (FVC) relative to Global Lung Function Initiative reference values (GLI2012) [10] versus absolute FEV1/FVC ratio in the study population ( $n=1323$ : males $n=596$; females $n=727)$. Fifth percentile lower limit of normal of z-score -1.645 and the Global Initiative for Chronic Obstructive Lung Disease criteria [34] fixed limit of FEV $/$ / $\mathrm{FVC}=0.70$ are indicated by dotted lines. 


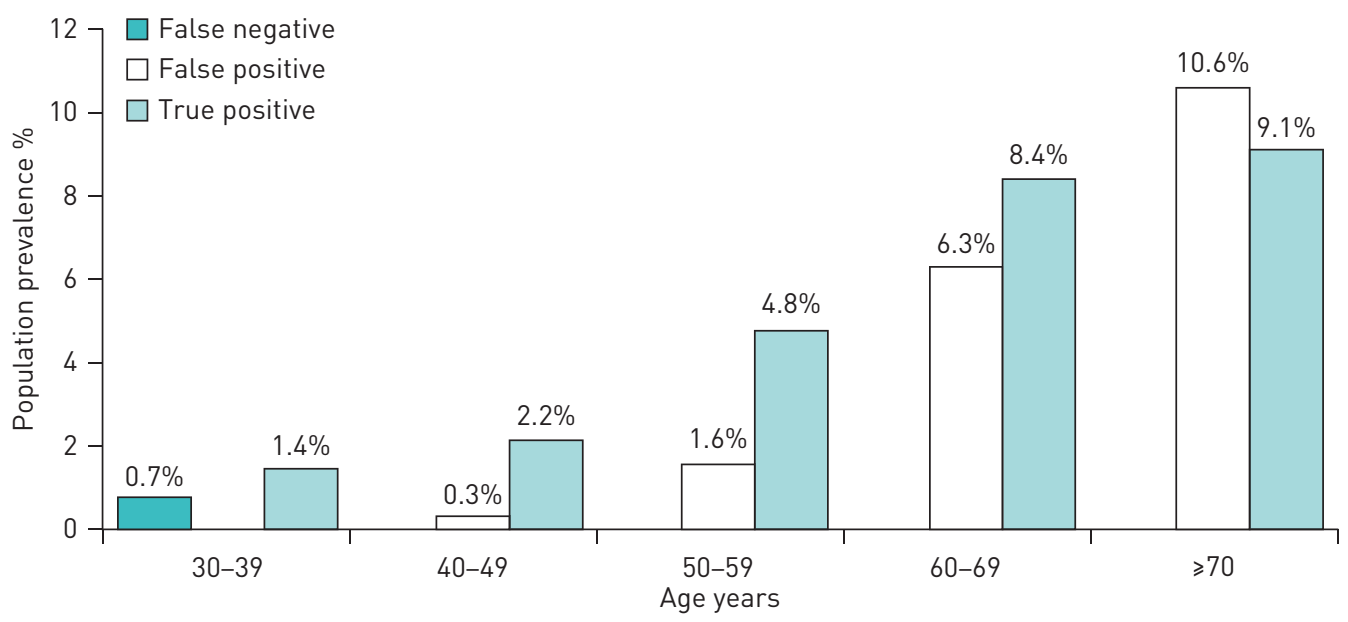

FIGURE 2 Prevalence of true-positive, false-negative and false-positive cases of chronic obstructive pulmonary disease identified with the fixed-limit Global Initiative for Chronic Obstructive Lung Disease criterion [34] using the Global Lung Function Initiative reference values (GLI2012) [10] as gold standard.

The use of more accurate criteria based on reference values has been limited by the variability of local reference values and the lack of a uniform definition of abnormal. The GLI2012 reference values provide a uniform definition for LLN for the first time [10]. We show that in a population-based sample in Finland the spirometric GOLD criteria overestimate COPD prevalence by $35 \%$ and up to $54 \%$ of cases in the oldest age category of $\geqslant 70$ years. Overdiagnosis starts already at age $50-59$ years where subjects with normal spirometry on LLN criteria would be diagnosed with airflow limitation consistent with COPD according to the GOLD criteria.

\section{Clinical relevance of diagnostic criterion for airflow limitation}

COPD is not a single disease but encompasses different diseases with varying prognosis [34]. It indicates a functional disorder characterised by a chronic and progressive reduction in maximum expiratory flow without clarifying the underlying mechanism [23]. There is no doubt that any diagnostic limit will have its limitations as well. Reduced FEV1/FVC is not a dichotomous variable, but instead a continuum of values including elevated, normal, borderline and significantly reduced values. ManNino et al. [16] have shown that subjects $\geqslant 65$ years of age with $\mathrm{FEV} 1 / \mathrm{FVC}<0.70$ but above their LLN were at an increased risk of death or COPD-related hospitalisation during an 11-year follow-up. The results were, however, contested after publication, with the rate of diagnosis and events labelled as COPD-related hospitalisations having been overly inclusive $[44,45]$. In a recent review by VAN DIJK et al. [32] evaluating the clinical significance of both criteria, the criteria based on reference values worked better in elderly subjects where discordant cases should be further evaluated for other diagnoses. The FEV1/FVC ratio is directly associated with FEV1, which has been shown to be one of the strongest predictors of all-cause morbidity and mortality

a)

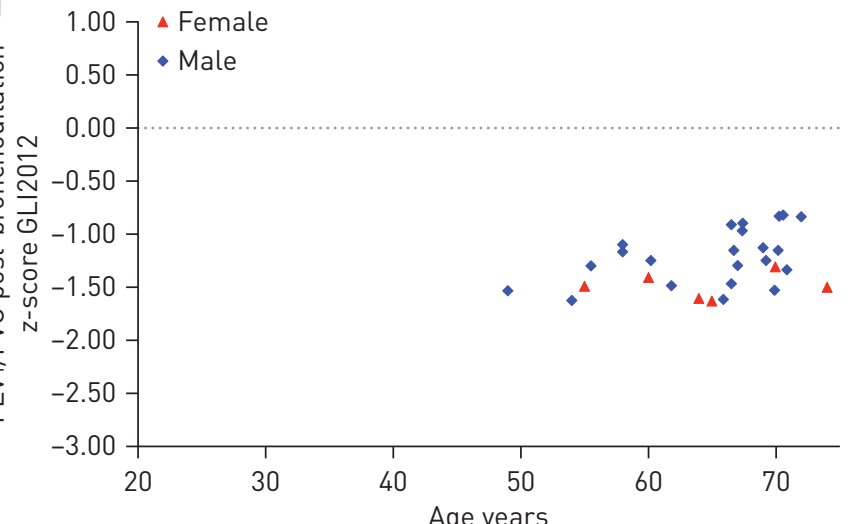

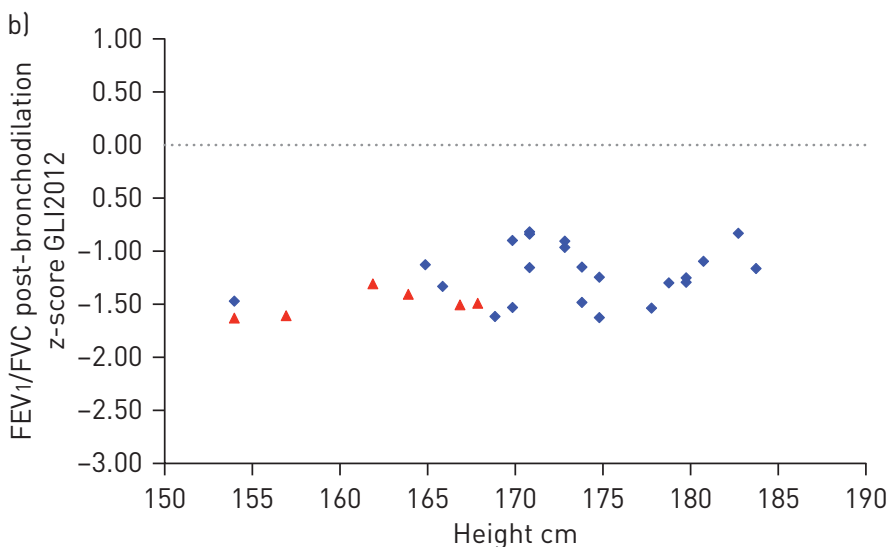

FIGURE 3 Level of forced expiratory volume in $1 \mathrm{~s}$ (FEV 1 )/forced vital capacity (FVC) post-bronchodilation as a function of a) age and b) height among subjects ( $n=28$ : males $n=6$; females $n=22$ ) with normal $F E V_{1} / F V C$ relative to Global Lung Function Initiative reference values (GLI2012) [10] (FEV $/$ FVC > lower limit of normal) but identified with airflow limitation on Global Initiative for Chronic Obstructive Lung Disease criterion [34] $(\mathrm{FEV} 1 / \mathrm{FVC}<0.70)$ in post-bronchodilation spirometry in the study population. 


\begin{tabular}{|c|c|c|c|c|c|c|c|c|}
\hline \multirow[t]{2}{*}{ Age years } & \multicolumn{4}{|c|}{ Male } & \multicolumn{4}{|c|}{ Female } \\
\hline & $\begin{array}{l}\text { True-positive } \\
\text { rate }\end{array}$ & $\begin{array}{l}\text { False-negative } \\
\text { rate }\end{array}$ & $\begin{array}{l}\text { False-positive } \\
\text { rate }\end{array}$ & $\begin{array}{l}\text { Proportion } \\
\text { of cases } \\
\text { false } \\
\text { positive }\end{array}$ & $\begin{array}{l}\text { True-positive } \\
\text { rate }\end{array}$ & $\begin{array}{c}\text { False-negative } \\
\text { rate }\end{array}$ & $\begin{array}{l}\text { False-positive } \\
\text { rate }\end{array}$ & $\begin{array}{c}\text { Proportion } \\
\text { of cases } \\
\text { false } \\
\text { positive }\end{array}$ \\
\hline$<30$ & 0.0 & 2.3 & 0.0 & 0.0 & 0.0 & 0.0 & 0.0 & 0.0 \\
\hline $30-39$ & 3.3 & 0.8 & 0.0 & 0.0 & 0.0 & 0.7 & 0.0 & 0.0 \\
\hline $60-69$ & 15.7 & 0.0 & 11.1 & 41.4 & 2.3 & 0.0 & 2.3 & 50.0 \\
\hline$\geqslant 70$ & 9.1 & 0.0 & 15.2 & 62.5 & 9.1 & 0.0 & 6.1 & 40.0 \\
\hline All & 5.7 & 0.3 & 3.7 & 39.3 & 2.5 & 0.1 & 0.8 & 25.0 \\
\hline
\end{tabular}

even in the absence of lung disease [46-49]. Subjects with a low but still normal FEV1/FVC ratio might be less healthy, and they do have lower lung function than their age and gender peers with higher FEV1/FVC ratio and normal FEV1, but this does not imply causality with the diagnostic criteria for COPD. A reduced FEV1/FVC ratio should be understood as a signal, but the diagnosis of COPD should be limited to truly abnormal values. The use of assessment based on reference values also facilitates better understanding of the grey areas around diagnostic criteria, i.e. a continuum of values around the LLN could improve the understanding of general practitioners of patients at risk. The predicted FEV1/FVC ratio is also an estimate with an associated degree of prediction error. Transition to the use of z-scores instead of percentage of predicted with the implementation of the GLI2012 reference values will improve the accuracy of the LLN especially in the elderly. Further research is needed to identify the significance of borderline categories of z-score combined with exposure and symptoms to possibly facilitate earlier identification of subjects at increased risk in primary care. However, airflow limitation is just one of the functional components of COPD. The addition of $\mathrm{FEV}_{1} \%$ pred and ratio of residual volume to total lung capacity has been found to improve the identification of clinically relevant COPD [50].

\section{Potential effect of height on degree of overdiagnosis of airflow limitation}

The continued use of FEV1/FVC fixed-limit criterion by GOLD guidelines has been advocated with similarities with the fixed limits agreed upon for other physiological measures such as elevated blood pressure [31]. There are, however, fundamental physiological differences in these variables. One of the most evident is

TABLE 4 Grading of degrees of airflow limitation in the study population ( $=1323$ ) according to the Global Initiative for Chronic Obstructive Lung Disease (GOLD) [34] and to QUANJER et al. [42] in subjects with lower limit of normal criteria airflow limitation (forced expiratory volume in $1 \mathrm{~s}$ (FEV1)/forced vital capacity (FVC) post-bronchodilation z-score <-1.645 on Global Lung Function Initiative reference values (GLI2012)] or with GOLD fixed-limit criterion (FEV1/FVC post-bronchodilation $<0.70$ )

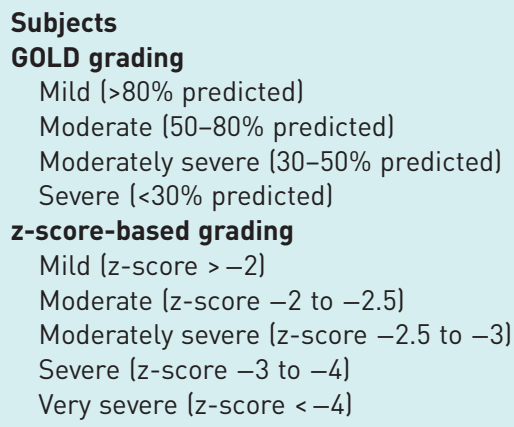

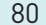

$\mathrm{FEV}_{1} / \mathrm{FVC}<0.70$

$F_{E V} /$ FVC $<$ LLN

Data are presented as $\mathrm{n}$ or $\%$ of subjects with airflow limitation. 


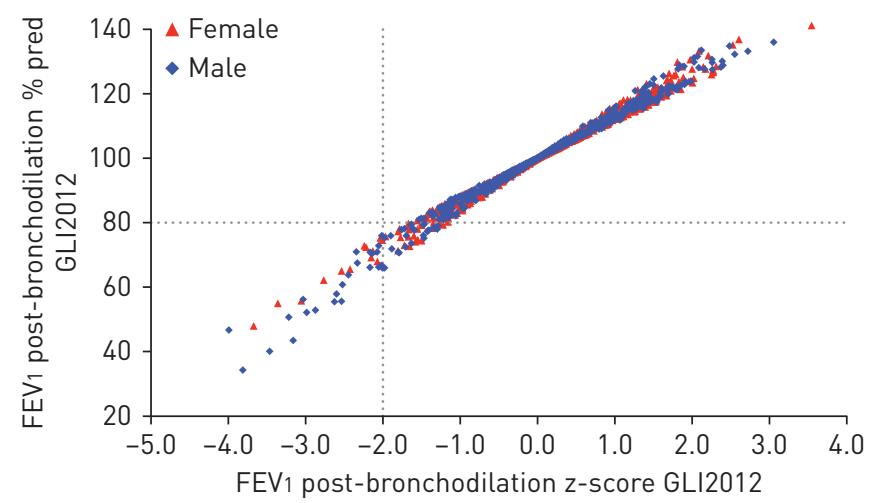

FIGURE 4 Distribution of forced expiratory volume in $1 \mathrm{~s}$ (FEV 1 ) relative to Global Lung Function Initiative reference values (GLI2012) [10] expressed as FEV1 \% pred versus FEV1 z-score stratified by sex (males $\mathrm{n}=596$; females $n=727)$. Reference values of $80 \%$ of predicted and $z$-score -2.0 are indicated by dotted lines.

the dependence of the FEV1/FVC ratio on a person's height. Using a fixed-limit criterion can cause an increasing level of overdiagnosis of airflow limitation with increasing height. Shorter subjects have normally higher ratios and taller subjects have physiologically lower ratios [10]. In our study the rate of false positives was not significantly higher in taller cohorts; however, of the false-positive cases, taller subjects had a significantly higher FEV1/FVC ratio relative to reference values (figure 3). Unfortunately the absolute number of obstructive individuals in our sample was too small for further analyses. Geographically, when comparing populations, taller populations could thus have higher rates of false positives. Additionally, the younger age cohorts in many countries are taller than their parents and grandparents. In Finland, the average height of the population increased by $5 \mathrm{~cm}$ in both males and females from the 1970s to the 2010s [51]. Thus, the level of overdiagnosis of airflow limitation using the FEV1/FVC fixed-limit criterion might have an increasing trend as taller generations are reaching middle age.

\section{Impact of overestimation with GOLD criteria}

The GOLD criteria were introduced to facilitate the interpretation of spirometry, which was considered difficult [1]. Generalisations can be useful, but they should not hinder correct diagnostics and treatment choices. In moderately to severely reduced FEV1, the GOLD criterion functions well and correct conclusions are reached even with this simplified "rule of thumb" [34]. These are also the patients that should be considered for COPD medication and among whom the results from pharmaceutical trials, using the inclusion criteria based on the GOLD criterion, are likely to be applicable to judge the costs and benefits of treatment. It is, however, the potential for harm that should drive pulmonary professionals towards change. All subjects benefit from the main treatment alternatives: quitting smoking, exercise, vaccinations and eating a healthy diet to maintain normal weight. The opportunity for harm is twofold: when pharmaceutical treatment is initiated to treat "reduced lung function" that is in fact normal and, moreover, when other reasons for shortness of breath, dyspnoea and other respiratory symptoms are not sought, when the patient is mislabelled as having COPD. There are no published studies that would have proven any benefit of treating subjects with normal lung function (without asthma) with inhaled steroids or long-acting bronchodilators, which on the contrary may have significant side-effects for the patients. The level of overestimation of airflow limitation, determined here as $35 \%$ of the population, can result in hugely excessive costs in terms of unnecessary pharmaceutical treatments.

\section{Grading of degree of airflow limitation}

We evaluated the grading system proposed by GOLD for applicability relative to z-score-based severity grading. The GOLD limits of $80 \%, 50 \%$ and $30 \%$ are not based on actual variability of FEV1 in healthy nonsmokers or subjects with COPD, but were originally chosen based on expert opinion as convenient limits that are easy to remember $[1,34]$. The GLI2012 reference values introduce individual z-scores, with increasing variation of lung function with age taken into consideration with a separately modelled coefficient of variation (S) [10]. Traditionally, a fixed limit of the fifth percentile, commonly $80 \%$ of predicted, has been considered as the LLN for all ages [10]. The true fifth percentile varies with age and what commonly is $80 \%$ of predicted in those $20-30$ years old is more likely $65-75 \%$ in the older age categories [10]. Thus, the use of z-scores to incorporate this variability gives a more accurate estimate of LLN, but also the degrees of reduced lung function, as seen in figure 3 and table 3. The GOLD limits fail to identify differences in FEV1 levels. Use of more accurate z-score-based grading of COPD could improve the grading of COPD and assessment of treatment options, even though airflow limitation is just one of the phenotypes of COPD [52]. 


\section{Limitations of the study}

There is no golden standard for the true prevalence of airflow limitation in the general population. Among healthy nonsmokers the recommended fifth percentile LLN should by definition identify $5 \%$ of subjects with reduced values. In the absence of a gold standard, comparisons between different diagnostic limits are relative. The population sample has a limited number of subjects with pathological airflow limitation consistent with COPD to assess, which limits further analysis. However, we have shown that the GLI2012 values differentiate between subjects with airflow limitation consistent with COPD and can potentially give severity grading of reduced ventilatory capacity more substance. Further studies on patient populations are needed to evaluate the grading system more thoroughly. The GLI2012 limit of z-score -3 would seem to correspond to the previous limit of $50 \%$ of predicted fairly well (figure 4 ). The low prevalence of airflow limitation found in the general population in comparison with other studies (table 1) is notable especially regarding various selection biases. However, compared with other Finnish studies from the same timespan (e.g. the Health 2000 study [41]), the population prevalences of GOLD criteria airflow limitation and smoking are similar. In addition, a nonresponder study was performed in Kemi, where the nonresponders were found to be more often smoking young men, which did not significantly affect survey results [39]. Airflow limitation consistent with COPD is prevalent in subjects $\geqslant 40$ years old and there was no difference in these age groups in terms of participation.

The GLI2012 reference values have been shown to underestimate lung volumes by $3-5 \%$ in the Finnish population, thus further study using severity grading from locally derived reference equations [39] is needed. Also in this study, the GLI2012 reference values would seem to underestimate lung volumes (FEV1), thus underestimating the degree of COPD by spirometric criteria, especially in females (table 3 and figure 4). The new Finnish reference values have been calculated with GAMLSS modelling similar to the GLI2012 model [53]. Local data can bridge the gap between GLI2012 and the clinical patient evaluation. However, this does not invalidate the use of GLI2012 reference values in international comparisons. Instead, the local data should be evaluated with models compatible with the modelling approaches taken with the Global Lung Function Initiative. The Global Lung Function Initiative has made software tools available to calculate correction factors for divergent population samples and it is foreseen that the Global Lung Function Initiative models will be further developed to incorporate new data in the future [10].

\section{Conclusions}

The GLI2012 reference values provide a uniform standard for the diagnosis of airflow limitation and should be used in lieu of the current GOLD criteria. Clinicians should be aware of the overestimation of airflow limitation and COPD resulting from the current widespread use of the fixed-limit GOLD criterion. One-third of cases identified with airflow limitation using the GOLD criterion had normal spirometry with GLI2012 reference values. Given the age distribution at the population level, this could result in potentially over half of cases identified being false positives. Overestimation of airflow limitation consistent with COPD in the middle aged and elderly can result in excessive pharmaceutical costs, side-effects of drugs used to treat COPD, and under-recognition of other causes of dyspnoea, cough and sputum production in the ageing population. We recommend the speedy recognition of GLI2012 as a uniform definition of airflow limitation in epidemiological research to substitute the spirometric GOLD criterion in the diagnosis of post-bronchodilation airflow limitation consistent with COPD.

\section{Acknowledgements}

We warmly thank the Research Unit of Pulmonary Diseases in Helsinki University Hospital for high-quality measurements and undertaking the FinEsS-Helsinki study, and Dr Jyrki-Tapani Kotaniemi (Päijät-Häme Central Hospital, Lahti, Finland) for overseeing the FinEsS-Kemi study.

\section{References}

1 Global Initiative for Chronic Obstructive Lung Disease. Global Strategy for the Diagnosis, Management and Prevention of Chronic Obstructive Pulmonary Disease. NHLBI/WHO Workshop Report. Bethesda, National Heart, Lung and Blood Institute, 2001.

2 Hardie JA, Buist AS, Vollmer WM, et al. Risk of over-diagnosis of COPD in asymptomatic elderly never-smokers. Eur Respir J 2002; 20: 1117-1122.

3 Roberts SD, Farber MO, Knox KS, et al. FEV $1 / \mathrm{FVC}$ ratio misclassifies patients with obstruction at the extremes of age. Chest 2006; 130: 200-206.

4 Hansen JE, Sun X-G, Wasserman K. Spirometric criteria for airway obstruction. Use percentage of FEV1/FVC ratio below the fifth percentile, not $<70 \%$. Chest 2007; 131: 349-355.

5 Cerveri I, Corsico AG, Accordini S, et al. Underestimation of airflow obstruction among young adults using FEV1/ FVC $<70 \%$ as a fixed cut-off: a longitudinal evaluation of clinical and functional outcomes. Thorax 2008; 63: $1040-1045$.

6 Schermer TR, Smeele U, Thoonen BP, et al. Current clinical guideline definitions for airflow obstruction leads to substantial overdiagnosis of COPD in primary care. Eur Respir J 2008; 32: 945-952.

7 Swanney MP, Ruppel G, Enright PL, et al. Using the lower limit of normal for the FEV1/FVC ratio reduces the misclassification of airway obstruction. Thorax 2008; 63: 1046-1051. 
8 Miller MR, Quanjer PH, Swanney MP, et al. Interpreting lung function data using 80 percent of predicted and fixed thresholds misclassifies over 20\% of patients. Chest 2011; 139: 52-59.

9 Vollmer WM, Gislason P, Burney P, et al. Comparison of spirometry criteria for the diagnosis of COPD: results from the BOLD study. Eur Respir J 2009; 34: 588-597.

10 Quanjer PH, Stanojevic S, Cole TJ, et al. Multi-ethnic reference values for spirometry for the 3-95-yr age range: the global lung function 2012 equations. Eur Respir J 2012; 40: 1324-1343.

11 Celli BR, Halbert RJ, Isonaka S, et al. Population impact of different definitions of airway obstruction. Eur Respir J 2003; 22: 268-273.

12 Hankinson JL, Oldencrantz JR, Fedan KB. Spirometric reference values from a sample of the general US population. Am J Respir Crit Care Med 1999; 159: 179-187.

13 Vanfleteren LEGW, Franssen FME, Wesseling G, et al. The prevalence of chronic obstructive pulmonary disease in Maastricht, the Netherlands. Respir Med 2012; 106: 871-874.

14 Scholes S, Moody A, Mindell JS. Estimating population prevalence of potential airflow obstruction using different spirometric criteria: a pooled cross-sectional analysis of persons aged 40-95 years in England and Wales. BMJ Open 2014; 4: e005685.

15 Hnizdo E, Glindmeyer HW, Petsonk EL, et al. Case definitions for chronic obstructive pulmonary disease. COPD 2006; 3: 95-100.

16 Mannino DM, Buist AS, Vollmer WM. Chronic obstructive pulmonary disease in the older adult: what defines abnormal lung function? Thorax 2007; 62: 237-241.

17 Perez-Padilla R, Hallal PC, Vásquez-Garcia JC, et al. Impact of bronchodilator use on the prevalence of COPD in population-based samples. COPD 2007; 4: 113-120.

18 Shirtcliffe P, Weatherall M, Marsh S, et al. COPD prevalence in a random population survey: a matter of definition. Eur Respir J 2007; 30: 232-239.

19 Roche N, Dalmay F, Perez T, et al. FEV1/FVC and FEV1 for the assessment of chronic airflow obstruction in prevalence studies: do prediction equations need revision? Respir Med 2008; 102: 1568-1574.

20 Quanjer PH, Tammeling GJ, Cotes JE, et al. Lung volumes and forced ventilatory flows. Report Working Party Standardization of Lung Function Tests, European Community for Steel and Coal. Official Statement of the European Respiratory Society. Eur Respir J 1993; 6: Suppl. 16, 5-40.

21 Falaschetti E, Laiho J, Primatesta P, et al. Prediction equations for normal and low lung function from the Health Survey for England. Eur Respir J 2004; 23: 456-463.

22 Vaz Fragoso CA, Concato J, McAvay G, et al. Chronic obstructive pulmonary disease in older persons: a comparison of two spirometric definitions. Respir Med 2010; 104: 1189-1196.

23 Stanojevic S, Wade A, Stocks J, et al. Reference ranges for spirometry across all ages. A new approach. Am J Respir Crit Care Med 2008; 177: 253-260.

24 Garcia-Rio F, Soriano JB, Miravitlles M, et al. Overdiagnosing subjects with COPD using the 0.7 fixed ratio: correlation with a poor health-related quality of life. Chest 2011; 139: 1072-1080.

25 Roca J, Burgos F, Sunyer J, et al. References values for forced spirometry. Group of the European Community Respiratory Health Survey. Eur Respir J 1998; 11: 1354-1362.

26 Lamprecht B, Schirnhofer L, Kaiser B, et al. Subjects with discordant airways obstruction: lost between spirometric definitions of COPD. Pulm Med 2011; 2011: 780215.

27 Waked M, Khayat G, Salameh P. Chronic obstructive pulmonary disease prevalence in Lebanon: a cross-sectional descriptive study. Clin Epidemiol 2011; 3: 315-323.

28 Danielsson P, Olafsdottir IS, Benediktsdottir B, et al. The prevalence of chronic obstructive pulmonary disease in Uppsala, Sweden - the Burden of Obstructive Lung Disease (BOLD) study: cross-sectional population-based study. Clin Respir J 2012; 6: 120-127.

29 Van Dijk W, Tan W, Li P, et al. Clinical relevance of fixed ratio vs lower limit of normal of FEV1/FVC in COPD: patient-reported outcomes from the CanCOLD cohort. Ann Fam Med 2015; 13: 41-48.

30 Turkeshi E, Vaes B, Andreeva E, et al. Airflow limitation by the Global Lungs Initiative equations in a cohort of very old adults. Eur Respir J 2015; 46: 123-132.

31 Di Marco F, Tantucci C, Pellegrino G, et al. Chronic obstructive pulmonary disease diagnosis: the simpler the better? Not always. Eur J Intern Med 2013; 24: 199-202.

32 Van Dijk WD, Gupta N, Tan WC, et al. Clinical relevance of diagnosing COPD by fixed ratio or lower limit of normal: a systematic review. COPD 2014; 11: 113-120.

33 Vestbo J, Hurd SS, Agusti AG, et al. Global strategy for the diagnosis, management and prevention of chronic obstructive pulmonary disease: GOLD executive summary. Am J Respir Crit Care Med 2013; 187: 347-365.

34 Global Initiative for Chronic Obstructive Lung Disease. Global Strategy for the Diagnosis, Management and Prevention of COPD - 2016. www.goldcopd.org Date last accessed: May 31, 2016.

35 Cole TJ, Green PJ. Smoothing reference centile curves: the LMS method and penalized likelihood. Stat Med 1992; 11: 1305-1319.

36 Backman H, Lindberg A, Sovijärvi A, et al. Evaluation of the global lung function initiative 2012 reference values for spirometry in a Swedish population sample. BMC Pulm Med 2015; 15: 26.

37 Kotaniemi J-T, Sovijärvi A, Lundbäck B. Chronic obstructive pulmonary disease in Finland: prevalence and risk factors. COPD 2005; 3: 331-339.

38 Kainu A, Lindqvist A, Sarna S, et al. FEV1 response to bronchodilation in an adult urban population and in healthy adults. Chest 2008; 134: 387-393.

39 Kotaniemi J-T, Hassi J, Kataja M, et al. Does non-responder bias have a significant effect on the results of a postal questionnaire study? Eur J Epidemiol 2001; 17: 809-817.

40 American Thoracic Society. Standardization of spirometry. 1994 update. Am J Respir Crit Care Med 1995; 152: 1107-1136.

41 Kanervisto M, Vasankari T, Laitinen T, et al. Low socioeconomic status is associated with chronic obstructive airway diseases. Respir Med 2011; 105: 1140-1146.

42 Quanjer PH, Pretto JJ, Drazzale DJ, et al. Grading the severity of airways obstruction: new wine in new bottles. Eur Respir J 2014; 43: 505-512.

43 GLI Team. Global Lung Function Initiative. www.ers-education.org/guidelines/global-lung-function-initiative.aspx Date last accessed: May 31, 2016. 
44 Mannino DM, Buist AS, Vollmer WM. Authors' reply to two letters to the editor. Thorax 2007; 62: 1108-1109.

45 Quanjer PH, Furberg CD. GOLD COPD stage I is not associated with increased risk of death. Respir Med 2012; 106: 153.

46 Ryan G, Knuiman MW, Divitini ML, et al. Decline in lung function and mortality: the Busselton Health Study. J Epidemiol Community Health 1999; 53: 230-234.

47 Schünemann HJ, Dorn J, Grant BJB, et al. Pulmonary Function is a long-term predictor of mortality in the general population: 29-year follow-up of the Buffalo Health Study. Chest 2000; 118: 656-664.

48 Stavem K, Aaser E, Sandvik L, et al. Lung function, smoking and mortality in a 26-year follow-up of healthy middle-aged males. Eur Respir J 2005; 25: 618-625.

49 Sin DD, Wu LL, Man SFP. The relationship between reduced lung function and cardiovascular mortality. A population-based study and a systematic review of the literature. Chest 2005; 127: 1952-1959.

50 Güder G, Brenner S, Angermann CE, et al. GOLD or lower limit of normal definition? A comparison with expert-based diagnosis of chronic obstructive pulmonary disease in a prospective cohort-study. Respir Res 2012; 13: 13 .

51 Helldán A, Helakorpi S. Health Behaviour and Health among the Finnish Adult Population, Spring 2014. Helsinki, National Institute for Health and Welfare, 2015.

52 Vaz Fragoso CA, Concato J, McAvay G, et al. Staging the severity of chronic obstructive pulmonary disease in older persons based on spirometric Z-scores. J Am Geriatr Soc 2011; 59: 1847-1854.

53 Kainu A, Timonen KL, Toikka J, et al. Reference values of spirometry for Finnish adults. Clin Phys Funct Imaging 2016; 36: 246-358 